\title{
PERANCANGAN DAN REALISASI ANTENA PHASED ARRAY MIKROSTRIP 1×4 X-BAND
}

\author{
Zillya Fatimah ${ }^{1}$, Heroe Wijanto², Yuyu Wahyu ${ }^{3}$ \\ ${ }^{1,2}$ ProdiS1 Teknik Telekomunikasi, Fakultas Teknik Elektro, Universitas Telkom \\ ${ }^{3}$ PPET-LIPI (Lembaga Ilmu Pengetahuan Indonesia) \\ ${ }^{1}$ zillya.fatimah@gmail.com, ${ }^{2}$ heroewijanto@telkomuniversity.ac.id, ${ }^{3}$ yuyu.wahyu@ppet.lipi.go.id
}

\begin{abstract}
Abstrak
Air Defense Radar merupakan radar pertahanan udara yang mampu mendeteksi target di udara yang meliputi posisi dan kecepatan. Sistem Air Defense Radar membutuhkan sebuah media transmisi berupa antena. Untuk sistem radar konvensional, antena diputar menggunakan rotator sehingga memungkinkan antena melakukan scanning area yang lebih luas jangkauannya. Dengan menggunakan aplikasi antena phased array akan memungkinkan dilakukan scanning secara elektrik, dimana dengan posisi antena yang tidak berubah tapi pola radiasi bisa diarahkan dengan cara mengendalikan fasa arus catu pada antena. Pada penelitian ini, antena dirancang dan disimulasikan dengan bantuan perangkat lunak dan direalisasikan menggunakan bahan substrat Rogers Duroid 5880 dengan nilai $\left(\varepsilon_{\mathrm{r}}=2,2\right.$ dan $\left.h=1,57 \mathrm{~mm}\right)$. Antena bekerja pada frekuensi $X$-Band $(9,37$ - 9,43 GHz) dengan VSWR di bawah $2(1,101,1,104,1,106$, dan 1,109), berpolarisasi linier, memiliki gain 18,636 dBi dan pola radiasi unidireksional. Antena memiliki dimensi 256,6 $\times 37,88 \times 1,535 \mathrm{~mm}$ serta mampu menggeser fasa secara elektrik sebesar $20^{\circ}$ dan $30^{\circ}$ saat variasi sudut fasa $70^{\circ}$ dan $90^{\circ}$ dengan menggunakan variasi kabel catu. Dengan spesifikasi tersebut antena phased array mampu bekerja dengan baik untuk Air Defense Radar.
\end{abstract}

Kata kunci: Antena Phased Array, Phase Shifter, X-Band

\section{Abstract}

Air Defense Radar is an air defense radar that capable of detecting targets in the air include the position and velocity. Air Defense Radar's system need a transmission medium that is antenna. For conventional radar system, radar antenna is rotated using rotator which allow the antenna scanning the area around them. The phased array antenna application allows electric scanning in the radar antenna, which is not change the position of antenna but the radiation pattern can be directed with controlling the supply current phase in the antenna. In this paper, antenna designed and simulated with software and realized using a substrate material Duroid Rogers 5880 with a value $\left(\varepsilon_{r}=2.2\right.$ and $\left.h=1.57 \mathrm{~mm}\right)$. Antenna works at a X-Band $(9.37$ - 9.43 GHz) frequency that produces VSWR are 1.101, 1.104, 1.106, 1.109, linear polarization, gain 18.636 dBi and undirectional radiation pattern. Antenna has $256.6 \times 37.88 \times 1.535 \mathrm{~mm}$ dimension and electrically able to shift the phase until $20^{\circ}$ and $30^{\circ}$ with phase difference of $70^{\circ}$ dan $90^{\circ}$ using a variation of supply cable. With these specification, the phased array antenna is work well for the performance of air defense radar.

Keywords: Antena phased array, Phase shifter, X-band

\section{Pendahuluan}

Radio Detection and Ranging (radar) adalah suatu sistem deteksi gelombang radio yang berguna untuk mendeteksi, mengukur jarak dan memetakan map benda-benda seperti pesawat terbang, militer, dan informasi cuaca. Untuk sistem radar konvensional, antena radar diputar menggunakan rotator sehingga memungkinkan antena melakukan scanning area sekitar antena. Dengan aplikasi antena phased array maka memungkinkan dilakukan scanning secara elektrik pada antena radar, dimana dengan posisi antena tidak berubah tetapi pola radiasi bisa diarahkan dengan mengendalikan fasa arus catu pada antenanya.

Dalam penelitian sebelumnya di rancang sebuah antena phased array pada frekuensi X-band menggunakan butler matrix [6]; dan pada penelitian [7] didesain phased array antenna 32 elemen untuk SAR; serta pada penelitian [8] didesain phased array antenna dengan desain antena dipole. Pada makalah ini, antena dirancang dan disimulasikan dengan bantuan perangkat lunak bantu yang memiliki desain antenna mikrostrip dan direalisasikan menggunakan bahan substrat Rogers Duroid 5880 dengan nilai $\left(\varepsilon_{\mathrm{r}}\right.$ $=2,2$ dan $h=1,57 \mathrm{~mm})$. Antena bekerja pada 
frekuensi $\quad X$-Band $\quad(9,37-\quad 9,43 \mathrm{GHz})$

\section{Metodologi}

\subsection{Desain Antena}

Spesifikasi dari Phased Array Antenna yang akan direalisasikan adalah sebagai berikut:

\subsection{Perhitungan Dimensi Antena Mikrostrip}

a. Frekuensi Tengah ${ }^{[1]}$

$$
\begin{aligned}
& f_{c}=\frac{f_{L}+f_{H}}{2}=\frac{9,37 \times 10^{9}+9,43 \times 10^{9}}{2}= \\
& 9,4 \times 10^{9}=9,4 G H z
\end{aligned}
$$

b. Panjang Gelombang [1]

$$
\lambda=\frac{C}{f c}=\frac{3 \times 10^{8}}{9,4 \times 10^{9}}=0,03 m=3,19
$$

[2]

c. Lebar Patch ${ }^{[11]}$

$$
\begin{gathered}
W=\frac{V o}{2 f r} \sqrt{\frac{2}{\varepsilon_{r}+1}}=\frac{3 \times 10^{8}}{2 \times 9,4 \times 109} \sqrt{\frac{2}{2,2+1}}= \\
0,0126154 \mathrm{~m}=12,615 \mathrm{~mm}
\end{gathered}
$$

d. Panjang Patch ${ }^{[11]}$

$$
\begin{gathered}
\epsilon_{\text {reff }}=\frac{\epsilon_{r}+1}{2}+\frac{\epsilon_{r}-1}{2}\left[1+12 \frac{h}{w}\right]^{-\frac{1}{2}}=\frac{2,2+1}{2}+\quad \\
\frac{2,2-1}{2}\left[1+12 \frac{1,5 \times 10^{-3}}{12,6 \times 10^{-3}}\right]^{-\frac{1}{2}}=1.9851 \\
\Delta L=0,412 h \frac{\left(\epsilon_{\text {reff }}+0,3\right)\left(\frac{w}{h}+0,264\right)}{\left(\epsilon_{\text {reff }}-0,258\right)\left(\frac{w}{h}+0,8\right)}= \\
0,412 h \frac{(3,0564+0,3)\left(\frac{12,61}{1,5}+0,264\right)}{(3,0564-0,258)\left(\frac{12,61}{1,5}+0,8\right)}=0,768 \mathrm{~mm} \\
L=\frac{1}{2 f r \sqrt{\epsilon_{r e f f}} \sqrt{\mu_{0} \epsilon_{0}}}-2 \Delta L= \\
\frac{1}{2 \times 9,4 \times 109 \sqrt{1,9851516} \sqrt{4 \pi \times 107 \times 8,85 \times 10-12}}-2 \Delta L= \\
9,782 \mathrm{~mm}
\end{gathered}
$$

e. Lebar Substrate ${ }^{[11]}$

$$
W_{s}=6 h+\text { Wpatch }=21,61 \mathrm{~mm}
$$

f. Panjang substrate ${ }^{[11]}$

$$
L_{s}=6 h+\text { Lpatch }=18,78 \mathrm{~mm}
$$

g. Lebar Saluran Transmisi ${ }^{[10]}$

$$
\begin{aligned}
& \frac{w}{h}= \\
& \left\{\begin{array}{l}
\frac{8 e^{A}}{e^{2 A-2}} \\
\text { untuk } \frac{w}{h}<2 \\
\left.\frac{2}{\pi}\left[\begin{array}{l}
B-1-\ln (2 B-1)+ \\
\frac{\varepsilon r-1}{2 \varepsilon r}\left\{\ln (B-1)+0,39-\frac{0,61}{\varepsilon r}\right\}
\end{array}\right]\right\} \\
\text { untuk } \frac{w}{h}>2 \\
\text { Karena } \frac{w}{h}, m a k a: \\
\circ B_{1}=\frac{377 \pi}{2 Z_{0} \sqrt{\varepsilon_{r}}}=\frac{377 \pi}{2 \times 200 \sqrt{2,2}}=1,996 \\
W_{1}=0,67 m m \\
\circ B_{2}=\frac{377 \pi}{2 Z_{0} \sqrt{\varepsilon_{r}}}=\frac{377 \pi}{2 \times 100 \sqrt{2,2}}=3,9924 \\
W_{2}=1,3 m m \\
\circ B_{3}=\frac{377 \pi}{2 Z_{0} \sqrt{\varepsilon_{r}}}=\frac{377 \pi}{2 \times 50 \sqrt{2,2}}=7,984 \\
W_{3}=4,59 m m
\end{array}\right\}
\end{aligned}
$$

h. Perhitungan panjang Saluran Transmisi ${ }^{[10]}$

$$
\begin{aligned}
& \lambda_{g}=\frac{\lambda_{0}}{\sqrt{\varepsilon_{\text {reff }}}}=\frac{0,03 \mathrm{~m}}{\sqrt{1,985}} \\
& =22 \mathrm{~mm} \\
& l_{f}=\frac{\lambda_{g}}{4}=5,662 \mathrm{~mm}
\end{aligned}
$$

i. Perhitungan Jarak Antar Elemen Antena ${ }^{[10]}$

$$
d=\frac{\tau}{2}=\frac{c}{2_{f}}=15 \mathrm{~mm}
$$

Tabel 1. Spesifikasi Antena yang dirancang

\begin{tabular}{|l|c|l|}
\hline Desain antena & $:$ & Phased Array $1 \times 4$ \\
\hline Jenis antena & $:$ & Phased array \\
\hline Frekuensi kerja & $:$ & X-Band $(9,37-9,43 \mathrm{GHz})$ \\
\hline Frekuensi tengah & $:$ & $9,4 \mathrm{GHz}$ \\
\hline VSWR & $:$ & $\leq 1,5$ \\
\hline Pola Radiasi & $:$ & Unidireksional \\
\hline Polarisasi & $:$ & Linear \\
\hline Gain & $:$ & $\geq 10 \mathrm{dBi}$ \\
\hline Impedansi & $:$ & $50 \Omega$ unbalance \\
\hline Bandwidth & $:$ & $\geq 50 \mathrm{MHz}$ \\
\hline Bahan PCB & $:$ & Rogers Duroid 5880 \\
\hline
\end{tabular}

Tabel 2. Hasil Simulasi Antena 16 Elemen 


\begin{tabular}{|c|c|c|c|c|}
\hline $\begin{array}{c}\text { Antena } \\
\text { port } \\
\text { ke- }\end{array}$ & $\begin{array}{c}\text { Frekuensi } \\
\text { Tengah }\end{array}$ & $\begin{array}{c}\text { Return } \\
\text { Loss }\end{array}$ & VSWR & $\begin{array}{c}\text { Bandw } \\
\text { idth } \\
\text { (MHz) }\end{array}$ \\
\hline 1 & 9,4 & $\begin{array}{c}- \\
26,058\end{array}$ & 1,104 & 448 \\
\hline 2 & 9,4 & $\begin{array}{c}- \\
25,674\end{array}$ & 1,109 & 441 \\
\hline 3 & 9,4 & $\begin{array}{c}- \\
25,674\end{array}$ & 1,109 & 440,5 \\
\hline 4 & 9,4 & $\begin{array}{c}- \\
26,058\end{array}$ & 1,104 & 445,8 \\
\hline
\end{tabular}

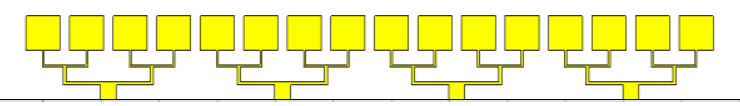

Gambar 2(a). Desain Antena Array Mikrostrip 16 elemen

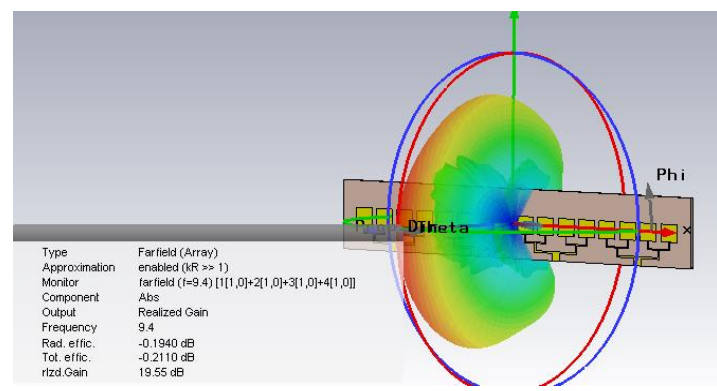

Gambar 2(b). Gain Antena Hasil Simulasi

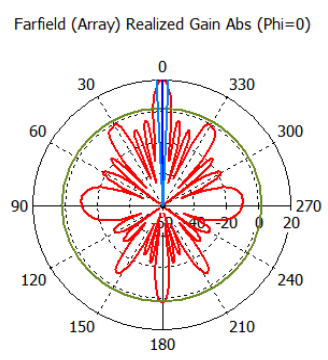

Theta / Degree vs. dB

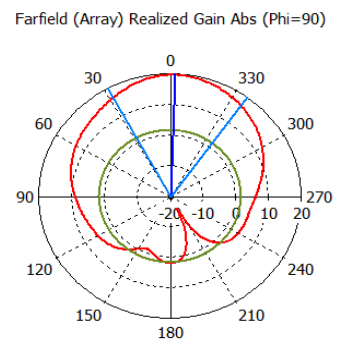

Theta / Degree vs. dB
Gambar 2(c). Hasil Simulasi Pola Radiasi (i) Azimuth (ii) Elevasi
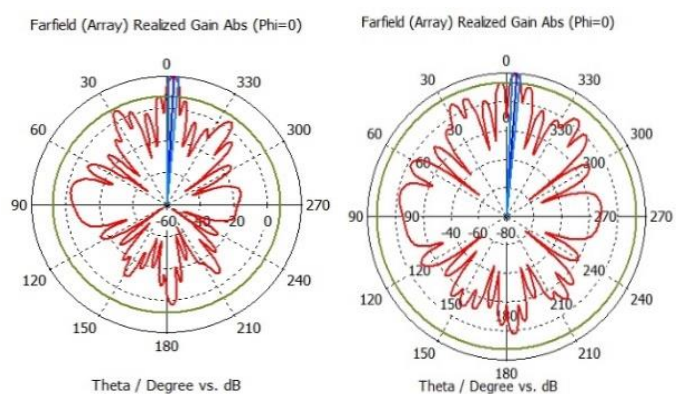

Gambar 2(d). Hasil Simulasi Pola Radiasi azimuth (i) Beda fasa $70^{\circ}$ (ii) Beda fasa $90^{\circ}$
Antena ini memiliki 4 modul, dimana masing masing modul terdiri dari 4 elemen antena, antena dibuat bersusun array agar memiliki gain $>10 \mathrm{~dB}$, Karena semakin banyak jumlah elemen suatu antena array gainnya akan semakin tinggi.

Pergeseran fasa pada gambar $2(\mathrm{~d})$ hasil pola radiasi di hasilkan pada beda fasa $70^{\circ}$ bergeser sebesar $3^{0}$ dengan besar gain $20,02 \mathrm{~dB}$ dan pada beda fasa $90^{\circ}$ bergeser $4^{0}$ dengan gain $19,37 \mathrm{~dB}$. Untuk perhitungan gain secara teoritis sebagai berikut:

$G_{\text {total }}=10 \log N+G_{\text {lelemen }}=$

$G_{\text {total }}=10 \log 16+6,911=18,952$

$G_{70^{0}}=18,952-0,05852=18,893$

$G_{90^{0}}=18,952-0,1145=18,8375$

Dari hasil gain yang dihasilkan sudah memenuhi spesifikasi antena radar yaitu gain harus $\geq 10 \mathrm{~dB}$. Pola radiasi azimuth dan elevasi bersifat unidireksional karena fokus ke satu arah, $0^{0}$ pada azimuth, $358^{\circ}$ pada arah elevasi. Hasil Frekuensi, Bandwidth, Return Loss, VSWR, impedansi, gain, pola radiasi sudah sesuai spesifikasi dan pergeseran sudut sebesar $3^{0}$ dan $4^{0}$ untuk masing-masing beda fasa $70^{\circ}$ dan $90^{\circ}$.

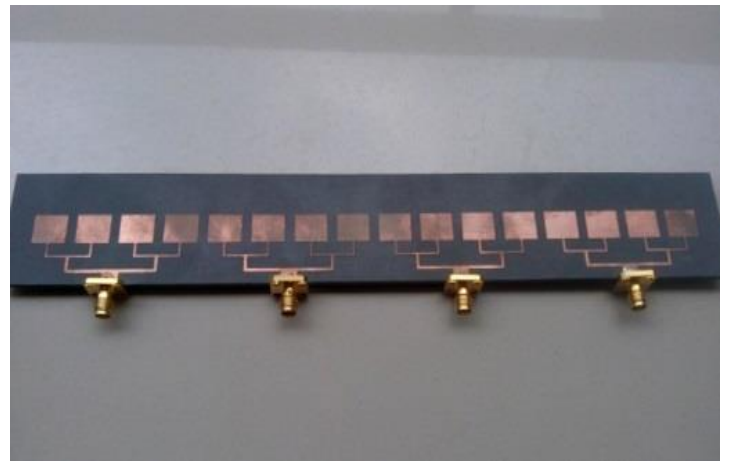

Gambar 3(a). Realisasi Antena Tampak Depan

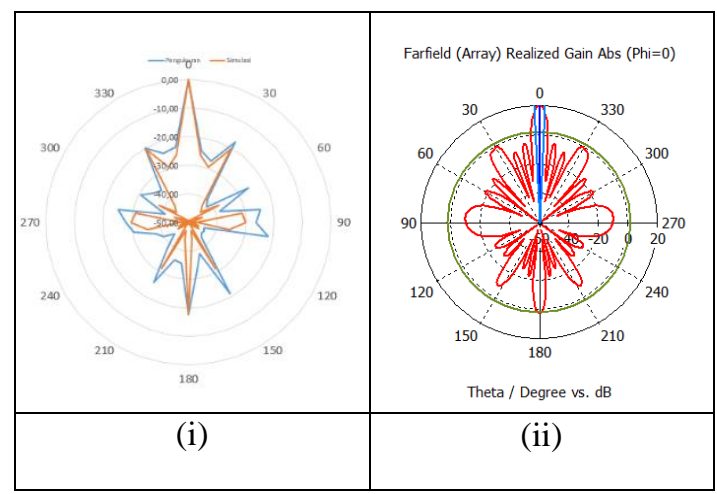

Gambar 3(b). Perbandingan Pola Radiasi Azimuth(i) Realisasi (ii) Simulasi

\subsection{Simulasi Software}



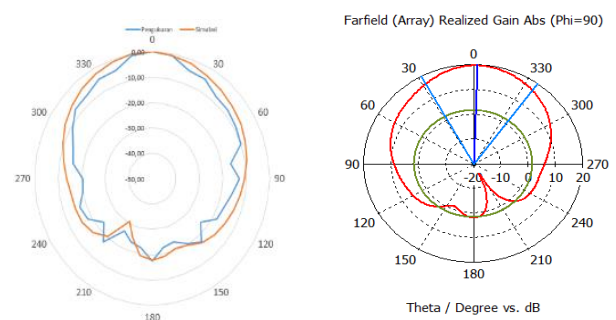

Gambar 3(c). Perbandingan Pola Radiasi Elevasi (i) Realisasi (ii) Simulasi
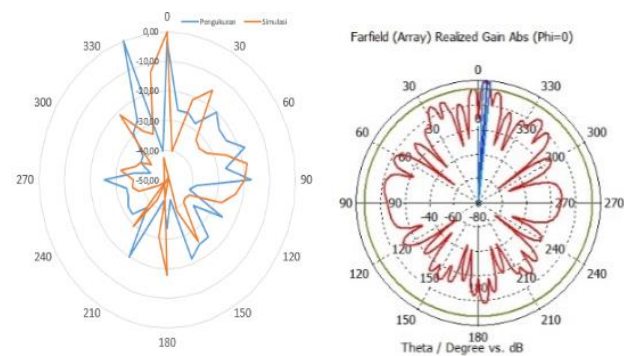

Gambar 3(d). Perbandingan Pola Radiasi 70 Elevasi (i) Realisasi (ii) Simulasi

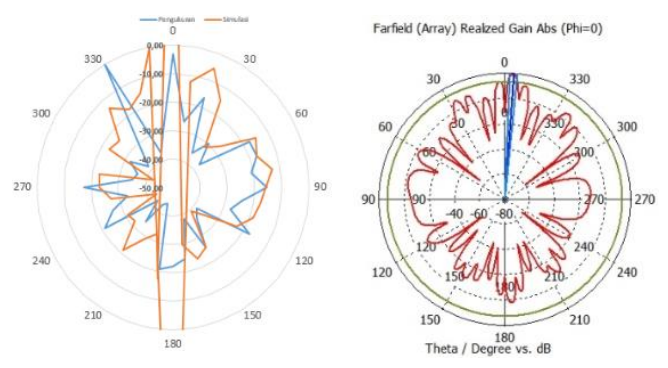

Gambar 3(e). Perbandingan Pola Radiasi 90 Elevasi (i) Realisasi (ii) Simulasi

Tabel 3(a). Hasil Pengukuran Return Loss, VSWR, Impedansi.

\begin{tabular}{|c|c|c|c|}
\hline \multicolumn{2}{|c|}{ Variasi Fasa $70^{\circ}$} & \multicolumn{2}{|c|}{ Variasi Fasa $90^{\circ}$} \\
\hline Beda Fasa & $\begin{array}{l}\text { Panjang } \\
\text { catuan } \\
\text { (cm) }\end{array}$ & Beda Fasa & $\begin{array}{l}\text { Panjang } \\
\text { catuan } \\
(\mathrm{cm})\end{array}$ \\
\hline$\frac{0^{0}}{360^{0}} \times \lambda=0 \lambda$ & 0 & $\frac{0^{0}}{360^{0}} \times \lambda=0 \lambda$ & 0 \\
\hline $\begin{array}{l}\frac{70^{0}}{360^{\circ}} \times \lambda= \\
0,194 \lambda\end{array}$ & 0,58 & $\begin{array}{l}\frac{90^{0}}{360^{0}} \times \lambda= \\
0,25 \lambda\end{array}$ & 0,75 \\
\hline $\begin{array}{l}\frac{140^{0}}{360^{0}} \times \lambda= \\
0,38 \lambda\end{array}$ & 1,166 & $\begin{array}{l}\frac{180^{0}}{360^{0}} \times \lambda= \\
0,5 \lambda\end{array}$ & 1,5 \\
\hline $\begin{array}{l}\frac{210^{0}}{360^{0}} \times \lambda= \\
0,583 \lambda\end{array}$ & 1,75 & $\begin{array}{l}\frac{270^{0}}{360^{0}} \times \lambda= \\
0,75 \lambda\end{array}$ & 2,25 \\
\hline
\end{tabular}

Tabel 3(b) Perhitungan Variasi Kabel Pencatu

\begin{tabular}{|c|c|c|c|}
\hline $\begin{array}{c}\text { Antena } \\
\text { port ke- }\end{array}$ & $\begin{array}{c}\text { Return } \\
\text { loss } \\
(\mathrm{dB})\end{array}$ & VSWR & $\begin{array}{c}\text { Bandwith } \\
(\mathrm{MHz})\end{array}$ \\
\hline 1 & $-26,354$ & 1,101 & 357 \\
\hline 2 & $-26,845$ & 1,104 & 582 \\
\hline 3 & $-28,649$ & 1,076 & 575 \\
\hline 4 & $-25,702$ & 1,109 & 732 \\
\hline
\end{tabular}

\section{Hasil dan Pembahasan}

Dimensi antena yang difabrikasi didapat ukuran $256,6 \times 37,88 \times 1,535 \mathrm{~mm}$. Antena di realisasikan dengan substrat Roger Duroid 5880 karena memiliki tangen loss yang rendah sehingga jumlah energi yang hilang (disipasi) akan bernilai rendah. Alat ukur yang digunakan yaitu Spectrum analyzer untuk pengukuran gain dan polaradiasi dari antena. Dalam penggunaannya, spectrum analyzer ditempatkan pada antena penerima (Rx) yang akan menampilkan level daya terima (RSL). Melalui pengukuran inilah dapat diketahui karakteristik level sinyal pada antena penerima. Sweep oscilator digunakan dalam pengukuran gain dan polaradiasi. Dalam pengukuran ini, sweep oscilator ditempatkan pada antena pemancar $(T x)$ yang berfungsi memberikan level daya dan frekuesi. Network analyzer digunakan dalam pengukuran VSWR, return loss, bandwidth, dan impedansi antena. Network analyzer akan menampilkan grafik hasil ukur berupa VSWR fungsi frekuensi, dan impedansi dalam bentuk smithchart.

\subsection{Hasil Pengukuran Return Loss, VSWR, Impedansi}

Berdasarkan perbandingan tabel diatas yang memberikan perbedaan hasil simulasi dengan hasil pengukuran. Nilai VSWR yang didapat dari pengukuran pada frekuensi $9,4 \mathrm{GHz}$ memiliki nilai $\leq$ 1,5, hal ini menunjukkan bahwa gelombang yang dipantulkan kembali ke arah generator bernilai kecil. Hal ini bisa berhubungan dengan nilai impedansi masukan dari kedua antena yang juga relative matching dengan saluran transmisi.

\subsection{Hasil Pengukuran Pola Radiasi Azimuth dan Elevasi}

Dari hasil yang diperoleh terlihat perbedaan pola radiasi baik pada arah azimuth maupun elevasi antara hasil pengukuran dan simulasi. Terdapat beberapa faktor: Pengukuran tidak dilakukan di ruangan anechoic chamber, Perangkat untuk pengukuran yang masih manual.

\subsection{Hasil Pengukuran Pola Radiasi dengan Phase Shifter}

Phase shifter yang digunakan pad pengujian ini 
adalah menggunakan variasi kabel pencatu, untuk penjelasanya sebagai berikut:

Pada pengukuran pola radisasi elevasi ini, hanya dilakukan pengukuran terhadap frekuensi kerja yaitu 9,4 GHz.

Pada saat realisasi fasa mengarah ke $20^{\circ}$ dan $30^{\circ}$ untuk masing-masing perubahan fasa $70^{\circ}$ dan $90^{\circ}$ Saat simulasi hanya $3^{0}$ dan $4^{0}$.

\subsection{Hasil Perhitungan Pola Radiasi dengan Prinsip Perkalian Diagram}

a. Antena 4 Elemen Isotropis

$$
\begin{aligned}
& E_{\text {tot }}=\sum_{i=1}^{4} A_{i} E_{0} e^{ \pm j \beta \Delta d} e^{ \pm j \alpha} \\
& E_{\mathrm{O} 1}=E_{\mathrm{O}} e^{-j \frac{2 \pi 6 \lambda}{\lambda 8} \sin \theta} e^{j . \mathrm{O}} \\
& E_{\mathrm{O} 1}=E_{\mathrm{O}} e^{-j \frac{3 \pi}{2} \sin \theta} \\
& E_{\mathrm{O} 2}=E_{\mathrm{O}} e^{-j \frac{2 \pi \lambda}{\lambda 4} \sin \theta} e^{j . \mathrm{O}} \\
& E_{\mathrm{O} 2}=E_{\mathrm{O}} e^{-j \frac{1 \pi}{2} \sin \theta} \\
& E_{\mathrm{O} 3}=E_{\mathrm{O}} e^{+j \frac{2 \pi \lambda}{\lambda 4} \sin \theta} e^{j . \mathrm{O}} \\
& E_{\mathrm{O} 3}=E_{\mathrm{O}} e^{+j \frac{1 \pi}{2} \sin \theta} \\
& E_{\mathrm{O} 4}=E_{\mathrm{O}} e^{+j \frac{2 \pi 6 \lambda}{\lambda 8} \sin \theta} e^{j . \mathrm{O}} \\
& E_{\mathrm{O} 4}=E_{\mathrm{O}} e^{+j \frac{3 \pi}{2} \sin \theta} \\
& E_{\text {tot }}=\sum_{i=1}^{4} A_{i} E_{0} e^{ \pm j \beta \Delta d} e^{ \pm j \alpha} \\
& =E_{0}\left[\begin{array}{c}
e^{-j \frac{3 \pi}{2} \sin \theta}+e^{+j \frac{3 \pi}{2} \sin \theta} \\
+e^{-j \frac{\pi}{2} \sin \theta}+e^{+j \frac{\pi}{2} \sin \theta}
\end{array}\right] \\
& E_{\text {tot }}=2 \cos \left(\frac{3 \pi}{2} \sin \theta\right)+2 \cos \left(\frac{\pi}{2} \sin \theta\right)
\end{aligned}
$$

b. Perhitungan Pergeseran Beda Fasa $70^{\circ}$ $E_{\text {TOTAL }}=E_{1}+E_{2}+E_{3}+E_{4}$

$$
\begin{aligned}
& =E_{\text {tot }}\left[\begin{array}{l}
e^{-j 6 \pi \sin \theta}+e^{+j 6 \pi \sin \theta} e^{j 210^{0}} \\
+e^{-j 2 \pi \sin \theta} e^{j 70^{0}} \\
+e^{+j 2 \pi \sin \theta} e^{j 140^{0}}
\end{array}\right] \\
& E_{\text {TOTAL }}=E_{\text {tot }}\left[\begin{array}{c}
\left(2 \cos \left(6 \pi \sin \theta+105^{0}\right)\right) \\
+\left(2 \cos \left(2 \pi \sin \theta+35^{0}\right)\right)
\end{array}\right] e^{j 105}
\end{aligned}
$$

c. Perhitungan Pergeseran Beda Fasa $90^{\circ}$

$$
\begin{aligned}
& E_{\text {TOTAL }}=E_{1}+E_{2}+E_{3}+E_{4} \\
& E_{\text {TOTAL }}=E_{\text {tot }}\left[\begin{array}{l}
e^{-j 6 \pi \sin \theta}+e^{-j 6 \pi \sin \theta} e^{j 270^{0}} \\
+e^{-j 2 \pi \sin \theta} e^{j 90^{0}} \\
+e^{-j 2 \pi \sin \theta} e^{j 180^{0}}
\end{array}\right] \\
& E_{\text {TOTAL }}=E_{\text {tot }}\left[\begin{array}{l}
\left(2 \cos \left(6 \pi \sin \theta+135^{0}\right)\right) \\
+\left(2 \cos \left(2 \pi \sin \theta+45^{0}\right)\right)
\end{array}\right] e^{j 135}
\end{aligned}
$$

Setelah mendapatkan hasil perhitungan pada pergeseran fasa $70^{\circ}$ dan $90^{\circ}$ lalu di kalikan dengan hasil pola radiasi antena satu-elemen yang identik dengan $\mathrm{n}$ antena isotropis yang telah di array untuk masing-masing fasa dan didapatkan pergeseran sudut untuk beda fasa $70^{\circ}$ dan $90^{\circ}$ adalah $5^{0}$ dan $7^{0}$
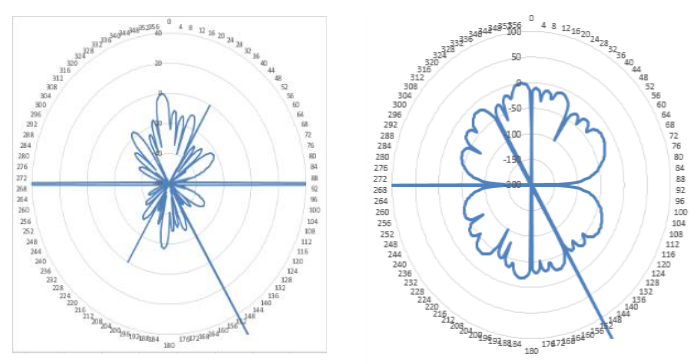

Gambar 3(f) Perhitungan pola radiasi beda fasa $70^{\circ}$ (i), Perhitungan pola radiasi beda fasa $90^{\circ}$ (ii)

Tabel 3(c) Tabel Perbandingan Hasil Simulasi Realisasi dan Perhitungan Menggunakan Phase Shifter

\begin{tabular}{|c|c|c|c|c|c|c|}
\hline \multirow{2}{*}{$\begin{array}{c}\text { Beda } \\
\text { fasa }\end{array}$} & \multicolumn{3}{|c|}{ Beam steering } & \multicolumn{3}{c|}{ Gain } \\
\cline { 2 - 7 } & $\begin{array}{c}\text { Simu } \\
\text { lasi }\end{array}$ & $\begin{array}{c}\text { Realisa } \\
\text { si }\end{array}$ & $\begin{array}{c}\text { Perhitu } \\
\text {-ngan }\end{array}$ & $\begin{array}{c}\text { Simul } \\
\text { asi }\end{array}$ & $\begin{array}{c}\text { Reali } \\
\text { sasi }\end{array}$ & $\begin{array}{c}\text { Perhitu } \\
\text {-ngan }\end{array}$ \\
\hline $70^{0}$ & $3^{0}$ & $20^{0}$ & $5^{0}$ & $\begin{array}{c}20,02 \\
\mathrm{~dB}\end{array}$ & $\begin{array}{c}18,53 \\
5 \mathrm{~dB}\end{array}$ & $\begin{array}{c}18,893 \\
\mathrm{~dB}\end{array}$ \\
\hline $90^{0}$ & $4^{0}$ & $30^{0}$ & $7^{0}$ & $\begin{array}{c}19,37 \\
\mathrm{~dB}\end{array}$ & $\begin{array}{c}17,25 \\
2 \mathrm{~dB}\end{array}$ & $\begin{array}{c}18,952 \\
\mathrm{~dB}\end{array}$ \\
& & & & & & \\
\hline
\end{tabular}

Perbedaan hasil simulasi dan realisasi dikarenakan pengukuran antena di lakukan tempat yang banyak pantulan sinyal lain sehingga data yang didapatkan 
kurang akurat, kurang presisinya panjang kabel catuan berdasarkan perhitungan serta Pengaruh perpanjangan dari kabel combiner Namun dengan melihat kedua hasil di atas menunjukkan bahwa terjadi pergeseran fasa dengan penambahan secara konstan.

\subsection{Hasil Pengukuran Gain}

Berdasarkan hasil pengukuran pada frekuensi 9,4 GHz didapatkan gain sebesar 18,636 dBi, ketika diarahkan pada sudut $70^{\circ}$ sebesar $18,535 \mathrm{dBi}$, ketika diarahkan pada sudut $90^{\circ}$ sebesar $17,252 \mathrm{dBi}$.

\subsection{Analisis Hasil Pengukuran}

Pada Hasil simulasi dan pengukuran Return Loss, Impedansi, Bandwidth, VSWR terdapat perbedaan. Nilai VSWR yang didapat dari pengukuran pada frekuensi $9,4 \mathrm{GHz}$ memiliki nilai $\leq 1,5$, hal ini menunjukkan bahwa gelombang yang dipantulkan kembali ke arah generator bernilai kecil. Hal ini bisa berhubungan dengan nilai impedansi masukan dari kedua antena yang juga relative matching dengan saluran transmisi, impedansi saluran transmisi pada rentang frekuensi 9,37 - 9,43 $\mathrm{GHz}$ menunjukkan nilai impedansi mendekati kurang lebih $50 \Omega$. Pada pengukuran pola radiasi dan gain terlihat perbedaan antara hasil pengukuran dan simulasi. Beberapa faktor yang menyebabkan adanya penyimpangan hasil pengukuran dibandingkan hasil simulasi, antara lain:

1. Perangkat untuk pengukuran yang masih manual seperti pengarahan sudut, sehingga pada saat pengarahan terdapat kemungkinan kesalahan sudut karena pengarahannya yang masih kurang tepat.

2. Kesalahan pembacaan level daya yang mungkin terjadi akibat fluktuasi daya terima yang terukur pada spectrum analyzer.

3. Terjadi ketidakstabilan jarak saat pengukuran, sehingga daya yang diterima tidak akurat.

4. Adanya gelombang dari luar sistem yang dapat mengganggu pola pancar dari antena

\section{Kesimpulan}

Kesimpulan yang dapat diambil dari seluruh proses perancangan dan realisasi Antena Phased Array 1x4 Elemen Mikrostrip adalah sebagai berikut:

1. Semua parameter antena diantaranya VSWR, bandwith, gain, dan pola radiasi memenuhi spesifikasi perancangan awal antena dan hasilnya tidak jauh berbeda dengan hasil simulasi.
2. Hasil Pergeseran sudut untuk beda fasa $70^{\circ}$ dan $90^{\circ}$ adalah sebesar $20^{\circ}$ dan $30^{\circ}$, hasil ini berbeda dengan simulasi diakibatkan karena pengukuran tidak dilakukan di ruang anechoic chamber sehingga terjadi banyak pantulan saat pengukuran dan juga disebabkan kurang presisinya panjang kabel catuan berdasarkan perhitungan serta pengaruh perpanjangan dari kabel combiner yang digunakan.

3. Pemasangan variasi kabel catuan pada antena yang berfungsi sebagai phase shifter dapat menggeser fasa pada pola radiasi antena, tetapi terdapat perbedaan antara hasil simulasi dan realisasi pengukuran.

\section{Daftar Pustaka}

[1] C. Balanis, Antena Theory: Analysis and Design, New York: Harper \& Row Publisher, 1982.

[2] Mailloux and R. J., Phased Array Antenna Handbook, 2005.

[3] Skolnik and M. I. , Introduction to Radar System, McGrawhill, 1980.

[4] Kraus and JohnD, Antennas For All Applications, New York: McGraw-Hill, 1961.

[5] K.Hussein and M.S.Mahdi, Design of Five Bit Digital Phase Shifter, 2012.

[6] Prasetyo and A. Hananto, Perancangan Dan Realisasi Antena Phassed Array Pada Fasa $0^{\circ}$ $180^{\circ}$ Untuk Efektivitas Peluru Kendali Atau Rudal Antikapal Pada Frekuensi X-Band (9.4 Ghz)., 2012.

[7] Prasetyo and A. Hananto, Perancangan Dan Realisasi Antena Phassed Array Pada Fasa $0^{\circ}$ $180^{\circ}$ Untuk Efektivitas Peluru Kendali Atau Rudal Antikapal Pada Frekuensi X-Band (9.4 Ghz)., 2012.

[8] A. A. Shafaat and P. SUPARCO, Karachi Design \& Development of a 32 Elements Xband Phased Array Antenna for Airborne \& Space Borne SAR Payloads, 2102.

[9] Firdaus and Sri Yusnita, Pengontrolan Polaradiasi Antena Array Dengan Antena individu Dipole $1 / 2$ Lambda, 2013.

[10] M.U.Afzal, A.A.Qureshi, M.A.Tarar and T.Taqueer, Modeling and Simulation of an Xband Planar Phased Array Antenna.

[11] Visser Hubregt j, Array and phased array antenna, 2005.

[12] Hansen and Robert C, Phased Array Antennas second edition, 2009. 